Proceedings of the $39^{\text {th }}$ IEEE

Conference on Decision and Control

Sydney, Australia - December, 2000

\title{
Speed Tracking Control with Maximal Power Transfer of Induction Motor
}

\author{
Hou-Tsan Lee', Li-Chen Fu' ${ }^{1,2}$ and Hsin-Shen Huang' \\ 1. Department of Electrical Engineering \\ 2. Department of Computer Science and Information Engineering \\ National Taiwan University, Taipei, Taiwan, R.O.C. \\ e-mail:lichen@csie.ntu.edu.tw
}

\begin{abstract}
This paper proposes a speed tracking control of induction motors based on the input/output linearization method, which can also achieve the maximal power transfer. A simple group of observers are designed to estimate the rotor flux in order to determine the orientation of rotor flux. The control law of the maximal power transfer to the rotor gives the relationship between the stator voltage and the orientation of rotor flux in d-q frame. The speed tracking controller is also robust with respect to the variation of rotor resistance and load torque. Simulation results are given to show the effectiveness of the presented controller. Experimental results are also given to validate the performances.
\end{abstract}

\section{Introduction}

It is well known that very often under the rather mild assumptions, the input/output response of a nonlinear system can be rendered linear via state feedback and coordinates transformation [1][2][3]. On the other hand, pioneered by Blachke [4], field orientation is the most popular technique for servo control of induction motor. The dynamic equations are nonlinear of fifth order for voltage-fed induction motor [5]. To achieve the desirable control objectives of induction motor, there are various kinds of nonlinear controllers. In most of the nonlinear controller of induction motor [6][7][8], the rotor flux is made to converge asymptotically to a fixed constant (or function), which is to prevent the saturation of the magnetic circuit. But, the flux saturation remains due to the resultant flux in the stator and the rotor [5], and hence the control schemes still can hardly achieve their original goals satisfactorily.

In recent researches, the sensorless control of induction motor [9][10][11] overcomes some problems when the motor serves in the rough conditions. The torque tracking problem [12][13] is also discussed to satisfy the varieties of the loads applied on induction motors. The nonlinear dynamical model of induction motor can be also rendered linear, too. Therefore, many kinds of control for induction motor via linearization are proposed [2][14], which try to solve the problems in familiar linear systems. The variation of rotor resistance is another challenge to the controls of induction motor. Several adaptive control schemes have been proposed to deal with this problem [16][17][18]. Certainly, the aforementioned techniques have made significant achievements in the area of induction motor control. But the property of power transfer of the induction motor is an important issue to discuss more.

Given the above observation, here we propose a simple controller for speed tracking of voltage-fed induction motor, which is with the property of maximal power transfer. [15] We find a simple control law to achieve the maximal power transfer to rotor by circuit analysis. The observers are then designed in a simple form to estimate the rotor flux. The variations of both torque and rotor resistance are considered in the simulations. Finally, the controller is proved strictly bounded stable and the 
simulation and experimental results are given to validate the effectiveness of the controller. Above all, the controller is with the property of maximal power transfer as the control law still matched, i.e. the voltage inputs involve with the orientation of rotor flux as described in next section.

\section{Field-Oriented Control with Maximal Power Transfer}

\section{(A) Dynamical model of induction motor:}

As has been well known, the dynamical model of an induction motor can be simplified by a d-q-axis coordinate transformation to some rotational-reference frame. But for implementation feasibility, the stationary-reference frame is more popularly used [5]. Thus, here we adopt the following group of $d$-q-axis coordinate-transformed dynamical equations of an induction motor:

$$
\begin{aligned}
& i_{q s}=-\alpha_{1} i q s+\alpha_{2} \lambda_{q r}-\beta p \omega_{r} \lambda_{d r}+c V_{q s} \\
& i_{d s}=-\alpha_{1} i d s+\beta p \omega_{r} \lambda_{q r}+\alpha_{2} \lambda_{d r}+c V_{d s} \\
& i_{q r}=\alpha_{3} i q s-\alpha_{4} \lambda_{q r}+p \omega_{r} \lambda_{d r} \\
& i_{d r}=\alpha_{3} i d s-\alpha_{4} \lambda_{d r}-p \omega_{r} \lambda_{q r} \\
& J \dot{\omega r}=T_{e}-T_{L} \\
& T_{e}=K\left(\lambda_{d r} i_{q s}-\lambda_{q r} i_{d s}\right),
\end{aligned}
$$

where the states and the parameters are defined as shown in the nomenclature.

\section{(B) Maximum Power Transfer of Induction Motor}

If the input voltages in $d-q$ frame of the voltage-fed induction motor are defined as:

$c V_{q s}=\frac{\lambda}{\sqrt{\lambda_{q r}^{2}+\lambda_{d r}^{2}}} V$, and $c V_{d s}=\frac{-\lambda_{q r}}{\sqrt{\lambda_{q r}^{2}+\lambda_{d r}^{2}}} V$
Then the power transferred to the rotor of an induction motor is maximal which subject to the constraint $\left(V_{q s}^{2}+V_{d s}^{2}\right)=(V / c)^{2}$ at any time. [15]

\section{Design of Observers and Controller}

\section{(a) Design of the flux observers}

In our assumptions, all the states and the parameters are measurable and known except the rotor flux. Therefore, we have to build a set of observers to estimate them.

$$
\begin{aligned}
& \hat{\lambda}_{q r}=\alpha_{3} i q s-\alpha_{4} \hat{\lambda}_{q r}+p \omega_{r} \hat{\lambda}_{d r} \\
& \hat{\lambda}_{d r}=\alpha_{3} i d s-\alpha_{4} \hat{\lambda}_{d r}-p \omega_{r} \hat{\lambda}_{q r}
\end{aligned}
$$

Lemma 1. If the dynamic equations are described as (1) with all the states being bounded and measured but rotor flux, then the flux observers designed as (3) can guarantee that $\hat{\lambda}_{d r}-\lambda_{d r} \rightarrow 0$ and $\hat{\lambda}_{q r}-\lambda_{q r} \rightarrow 0$ as $t \rightarrow \infty$.

\section{Proof:}

Let the observation errors be denoted as $e_{d}=\hat{\lambda}_{d r}-\lambda_{d r}$ and $e_{q}=\hat{\lambda}_{q r}-\lambda_{q r}$. Choose the Lyapunov's function candidate to be a quadratic form as

$V=\frac{1}{2}\left[e_{d}{ }^{2}+e_{q}{ }^{2}\right]$. Therefore, the differential equation is obtained as $\dot{V}=-\alpha_{4}\left[e_{d}^{2}+e_{q}^{2}\right]$.

Then, by straightforward derivations and application of Lyapunov's Theorem [19], we can guarantee that $\hat{\lambda}_{d r}-\lambda_{d r} \rightarrow 0$ and $\hat{\lambda}_{q r}-\lambda_{q r} \rightarrow 0$ as $t \rightarrow \infty$. Q.E.D.

\section{(b) Design of the controller}

We further simplify the dynamics shown in (1) by 
introducing the input/output linearization [2]. The rotor resistance and load torque may have a range of variations up to $\pm 50 \%$ around their nominal values, respectively, denoted as $R_{r}$ and $T_{L}$. Define the change of coordinates as follows:

$$
\begin{aligned}
& z_{1}=\omega_{r} \\
& z_{2}=\mu\left(i_{q s} \lambda_{d r}-i_{d s} \lambda_{q r}\right)-\frac{T_{b}}{J} \\
& z_{3}=\lambda_{q r}^{2}+\lambda_{d r}^{2} \\
& z_{4}=-2 \alpha_{4}\left(\lambda_{q r}^{2}+\lambda_{d r}^{2}\right)+2 \alpha_{3}\left(i_{q s} \lambda_{q r}+i_{d s} \lambda_{d r}\right)
\end{aligned}
$$

which can be shown one-to-one over the domain

$$
\Omega=\left\{x \in R_{5}: \lambda_{d r}^{2}+\lambda_{q r}^{2} \neq 0\right\} \text { but is onto only over } z_{3}>0 .
$$

The dynamical equations can be rewritten with (2) as follows

$$
\begin{aligned}
& \dot{z}_{1}=z_{2} \\
& \dot{z}_{2}=f_{1}+\mu \sqrt{\lambda_{d r}^{2}+\lambda_{q r}^{2}} \mathrm{~V} \\
& \dot{z}_{3}=z_{4} \\
& \dot{z}_{4}=f_{2}=-c_{1} z_{3}-c_{2} z_{4}+f_{3} \\
& =-\left(2 \alpha_{4} \alpha_{1}+2 \alpha_{4}^{2}+2 \alpha_{2} \alpha_{3}\right) z_{3}-\left(\alpha_{1}+3 \alpha_{4}\right) z_{4}+\left[2 \alpha_{3}^{2}\left(i_{d s}^{2}+i_{q s}^{2}\right)+{ }_{3}^{4} \omega_{r} R_{r} T_{e}\right] \\
& y=z_{1}=\omega_{r}
\end{aligned}
$$

where the parameters are defined in the nomenclature with $f_{1}=-\mu p \omega_{r}\left(\lambda_{d r}^{2}+\lambda_{q r}^{2}\right)-\mu\left(\alpha_{1}+\alpha_{4}\right)\left(i_{q s} \lambda_{d r}-i_{d s} \lambda_{q r}\right)-\mu p \omega_{r}\left(i_{q s} \lambda_{q r}+i_{d s} \lambda_{d r}\right)$, $f_{2}=\left(4 \alpha_{4}^{2}+2 \alpha_{2} \alpha_{3}\right)\left(\lambda_{d r}^{2}+\lambda_{q r}^{2}\right)+2 \alpha_{3} p \omega_{r}\left(i q s \lambda_{d r}-i d s \lambda_{q r}\right)-\left(2 \alpha_{1} \alpha_{3}+6 \alpha_{3} \alpha_{4}\right)$

$$
\left(i_{q s} \lambda_{q r}+i_{d s} \lambda_{d r}\right)+2 \alpha_{3}^{2}\left(i_{d s}^{2}+i_{q s}^{2}\right) .
$$

Where $c_{1}, c_{2}$ are larger than zero. Therefore, the subsystem described by the last two equations of system (4) is a BIBS (bounded-input bounded-state) system provided $f_{3}$ is bounded. Now, if

$$
V=\left(\mu \sqrt{\lambda_{d r}^{2}+\lambda_{q r}^{2}}\right)^{-1}\left(-f_{1}+U\right)
$$

then the first two equations of system (11) become

$$
\dot{z}_{1}=z_{2}, \dot{z}_{2}=U
$$

To solve the speed-tracking problem still with maximal power transfer, the input signal $U$ is designed as

$$
U=-k_{1}\left(z_{1}-\omega_{d}\right)-k_{2}\left(z_{2}-\dot{\omega}_{d}\right)+\ddot{\omega}_{d},
$$

where $\omega_{d}$ is the reference signal of rotor speed.

Theorem 1. If the I/O linearized system (4) with the control input $V$ being defined in (5) and bounded, where

$U$ is given by (6), with $\omega_{d}, \dot{\omega}_{d}$, and $\ddot{\omega}_{d}$ being all bounded, then the system (4) is bounded stable.

\section{Proof:}

Substitute the control input (5) and (6), into system (4), then system (4) can be re-expressed as

$$
\left[\begin{array}{l}
\dot{z_{1}} \\
\dot{z_{2}} \\
\dot{z_{3}} \\
\dot{z}_{4}
\end{array}\right]=\left[\begin{array}{cccc}
0 & 1 & 0 & 0 \\
-k_{1} & -k_{2} & 0 & 0 \\
0 & 0 & 0 & 1 \\
0 & 0 & -c_{1} & -c_{2}
\end{array}\right]\left[\begin{array}{l}
z_{1} \\
z_{2} \\
z_{3} \\
z_{4}
\end{array}\right]+\left[\begin{array}{l}
0 \\
f_{4} \\
0 \\
f_{3}
\end{array}\right],
$$

where $f_{3}$ is defined in (4) and $f_{4}=k_{1} \omega_{d}+k_{2} \dot{\omega}_{d}+\ddot{\omega}_{d}$ 
is always bounded. To prove the property of BIBS, we separate the procedure into two parts:

First, the states $z_{1}$ and $z_{2}$ are apparently bounded since the parameters $k_{1}, k_{2}>0$ and $f_{4}$ is bounded.

Second, since the electric torque is bounded (proportional to $\mathrm{z}_{2}$ ) then by the property that $\omega_{3} \cdot T=P_{s}$, we conclude the input power is bounded. On the other hand, the relation between the input power and the stator voltage and current is $P_{s}=3\left(V_{s} \cdot I_{s} \cdot \cos \delta\right)$ where $\delta$ is the angle between stator voltage and current. Then, $V_{s}^{2} \cdot I_{s}^{2} \cdot \cos ^{2} \delta$ is bounded since $P_{s}$ is bounded. And, $V_{s}^{2}$ is bounded by the input voltage limit. Thus, $I_{s}^{2}=I_{d s}^{2}+I_{q s}^{2}$ is bounded. As a result, $f_{3}$ is bounded since all the signals of $f_{3}$ are bounded. Therefore, the system (4) is indeed bounded stable.

Q.E.D.

\section{Simulation and experimental Results}

In this section, the performances of the proposed controller, which is applied to an induction motor, will be demonstrated by a number of simulation results. The characteristics of the induction motor are listed as below:

$R_{s}=0.83 \Omega, R_{r}=0.83 \Omega, L_{s}=0.08601(\mathrm{H}), L_{r}=0.08601(\mathrm{H})$, $L_{m}=0.08259(\mathrm{H}), J_{m}=0.033\left(\mathrm{Kg}-\mathrm{m}^{2}\right), 4$ poles, rated current 8.6 A, $220 \mathrm{~V}, 60 \mathrm{~Hz}, \mathrm{AC}$.

Fig. 1 and Fig. 2 show the robustness with respect to the variation of rotor resistance and load torque by simulation. Fig. 3 shows the experimental results of step and ramp speed tracking. Fig. 4 shows the effect of maximal power transfer property, the stator current of the proposed scheme is less than ref[2] with same speed tracking (120 rad/sec) based on $\mathrm{I} / \mathrm{O}$ linearization.

\section{Conclusion}

In this paper, we have proposed a field-oriented input/output linearization controller for an induction motor with a new control law, which can achieve the maximal power transfer into the rotor of an induction motor. And, it can also withhold variations of both rotor resistance and load torque up to the range of $\pm 50 \%$. Simulations validate the performances mentioned above. The proposed control scheme only uses the rotor speed and the orientation of the rotor flux as feedback information. And, the rotor flux can be easily estimated with the simple observers designed in this paper. The controller hence becomes a plausible scheme. The experimental results are also given to validate the performances. There are some concluding remarks should be noted here:

1. The desired constant speed command can be directly input to the controller without modification into a smooth function.

2. The speed ripple and stator current both less than the comparison scheme of ref[2].

3. Numerical simulations and experimental results validate the properties of the proposed control scheme.

4. The further work of sensorless indirect control with unknown rotor resistance and unknown load torque can deal with the problem of unknown parameters (states).

\section{Reference}

[1] S. S. Sastry, and A. Isidori, "Adaptive Control of Linearizable Systems," IEEE Trans. Automat. Contr., Vol. 34, No. 11, pp. 1123-1131, 1989.

[2] R. Marino, and P. Tomei, Nonlinear Control DesignGeometric, Adaptive and Robust, London, U.K. : Prentice Hall, 1995.

[3] R. Marino, S. Peresada, and P. Tomei, "Global Adaptive Output Feedback Control of Induction Motors with Uncertain Rotor Resistance," IEEE Trans. Automat. Contr., Vol. 44, No. 5, pp. 967-983, 1999.

[4] F. Blaschke, "The principle of Field Orientation Applying to the New Transvector Closed-Loop Control System for Rotation Field Machines," Siemens-Rev., Vol. 39, pp. 217-220, 1972. 
[5] P. C. Krause, Analysis of Electric Machinery, McGraw-Hill, 1986.

[6] I. Kanellakopoulos, and P. K. Krein, "Integral-action Nonlinear Control of Induction Motors," $12^{\text {th }}$ IFAC World Congress (Sydney)., pp. 251-254, 1993.

[7] R. M. Marino, S. Peresada, and P. Valigi, "Adaptive Input-Output Linearlization Control of induction Motors," IEEE Trans. Automat. Contr., Vol. 38, No. 2, pp. 208-221, 1992.

[8] P. Aquino, M. Feemster, D. M. Dawson, and A. Behal, "Adaptive Partial State Feedback Control of the Induction Motor: Elimination of Rotor Flux And Rotor Velocity Measurements," Proc. $37^{\text {h }}$ IEEE CDC., Tampa, USA., 1998.

[9] H. Tajima, and Y. Hori, "Speed Sensorless FieldOrientation Control of Induction Machine," IEEE Trans. Indust. Appl., Vol. 29, No. 1, pp. 175-180, 1993.

[10] M. Bodson, J. Chiasson, and R. T. Novotnak, "Nonlinear Speed Observer for High-Performance Induction Motor Control," IEEE Trans. Indust. Electron., Vol. 42, No. 4, pp. 337-343, 1995.

[11] H. Kubota, and K. Matsuse, "Speed Sensorless FieldOriented Control of Induction Motor with Rotor Resistance Adaptation," IEEE Trans. Indust. Appl., Vol. 30, No. 5, pp. 1219-1224, 1994.

[12] G. Espinosa, R. Ortega, and P. J. Nicklasson, "Torque and Flux Tracking of Induction Motors," Int. $J$. Robust \& Nonlinear Contr, Vol. 7, pp. 1-9, 1997.

[13] R. Ortega, C. Canudas, and S. I. Seleme, "Nonlinear Control of Induction Motors : Torque Tracking with Unknown Load Disturbance," IEEE Trans. Automat. Contr., Vol. 38, No. 11, pp. 1675-1680, 1993.

[14] R. M. Marino, S. Peresada, and P. Valigi, "Adaptive Input-Output Linearization Control of Induction Motors," IEEE Trans. Autom. Contr., Vol. 38, pp. 208-
221, 1993.

[15] H. T. Lee, J. S, Chang, and L. C. Fu, "Exponentially Stable Non-linear Control for Speed Regulation of Induction Motor with Field-Oriented PI-Controller", International Journal of Adaptive Control and Signal Processing, Vol.14, pp.297-312, 2000.

[16] R. M. Mario, S. Peresada, and P. Tomei, "Adaptive Observer-Based Control of Induction Motor with Unknown Rotor Resistance," Int. J. Adapt. Contr. \& Signal Porc., Vol. 10, pp. 345-363, 1996.

[17] R. M. Marino, S. Peresada, and P. Valigi, "Output Feedback Control of Current-Fed Induction Motors with Unknown Rotor Resistance," IEEE Trans. Contr. Syst. Tech., Vol. 4, No. 4, pp. 336-347, 1996.

[18] R. M. Marino, S. Peresada, and P. Tomei, "Global Adaptive Output Feedback Control of Induction Motor with Unknown Rotor Resistance," IEEE Trans. Autom. Contr., Vol. 44, No. 5, pp. 967-983, 1999.

[19] M. Vidyasagar, Nonlinear Systems Analysis, PrenticeHall, Inc., New Jersey, 1993.

\section{Nomenclature}

$i_{q s}\left(i_{d s}\right): \quad \mathrm{q}-(\mathrm{d}-)$ axis input stator current

$R_{s}\left(R_{r}\right)$ : stator (rotor) resistance

$V_{q s}\left(V_{d s}\right): \quad q-(\mathrm{d}-)$ axis input stator voltage

$L_{s}\left(L_{r}\right): \quad$ stator (rotor) inductance

$\lambda_{\text {gr }}\left(\lambda_{d r}\right): \quad \mathrm{q}-(\mathrm{d}-)$ axis rotor flux

$\omega_{r}: \quad$ rotor speed

$T_{e}$ : electromagnetic torque, $T_{L}: \quad$ load torque

$L_{m}:$ mutual inductance, $\quad P:$ number of pole pairs

$J:$ inertia of the rotor, $\quad D=\left(L_{s} L_{r}-L_{m}^{2}\right)$

$\beta=L_{m} / D, \quad c=L_{r} / D$

$\alpha_{1}=\left(R_{s} L_{r}\right) / D+\beta \alpha_{3}, \quad \alpha_{2}=\beta \alpha_{4}$

$\alpha_{3}=L_{m} \alpha_{4}, \quad \alpha_{4}=R_{r} / L_{r}$

$K_{l}=3 P L_{m} / 2 L_{r}, \quad \mu=K_{t} / J$ 

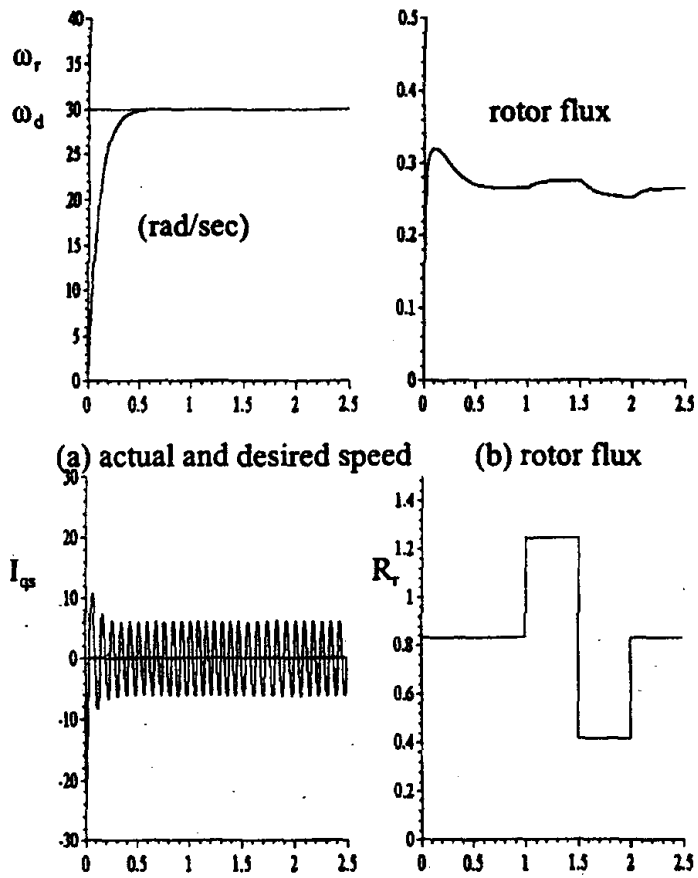

(c) stator current

Fig. 1 Speed $=30(\mathrm{rad} / \mathrm{sec})$ with $k_{1}=5000$, with variation of $R_{T}$ ( $50 \%$ shift )
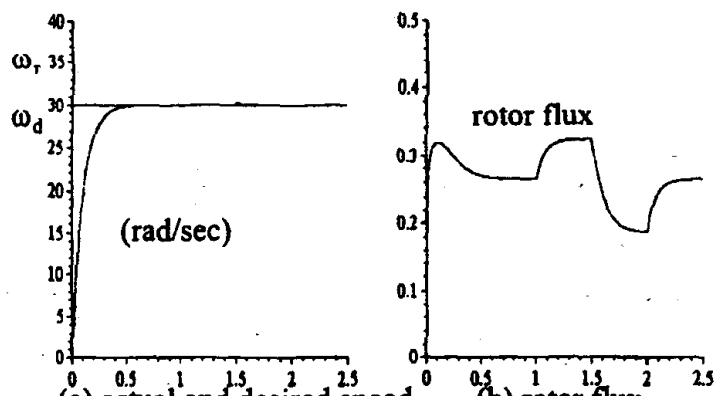

$\begin{array}{ll}\text { (a) actual and desired speed } & 2.9 \\ & \text { (b) rotor flux }\end{array}$

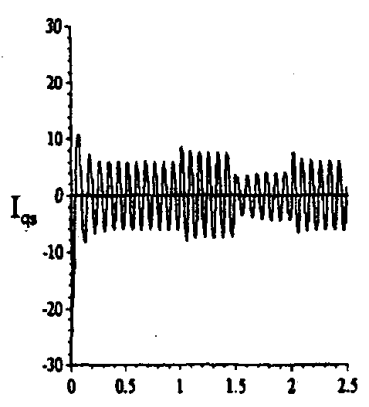

(c) stator current

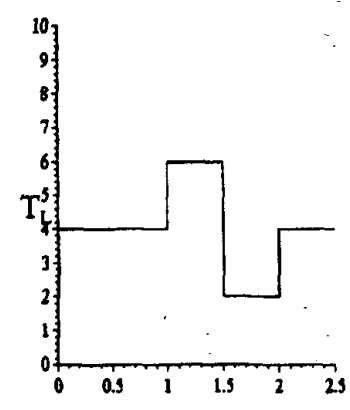

(d) variation of $T_{L}$
Fig.2 Speed $=30(\mathrm{rad} / \mathrm{sec})$ with variation of $T_{L}$
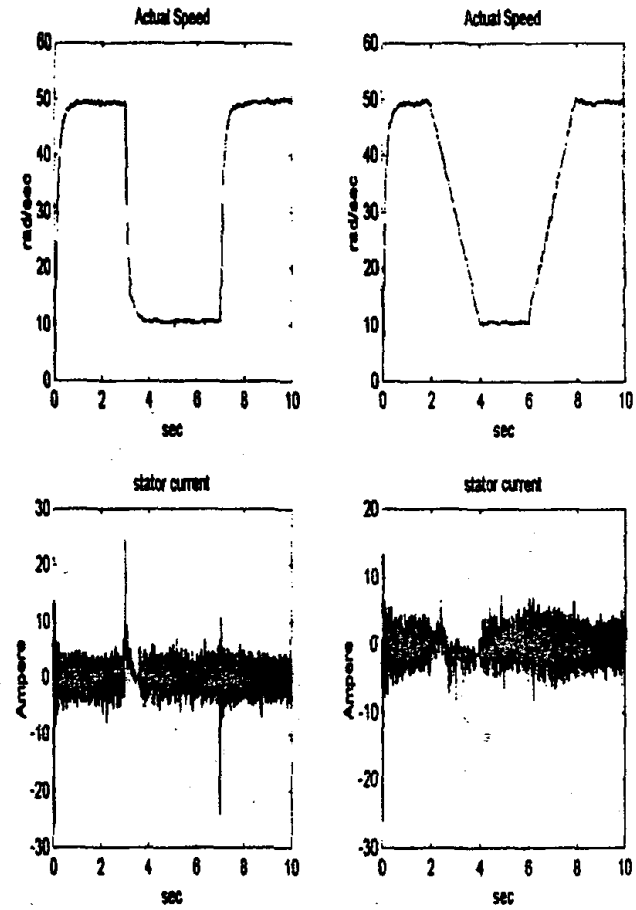

Fig. 3 Experimental results of ramp and step functions.
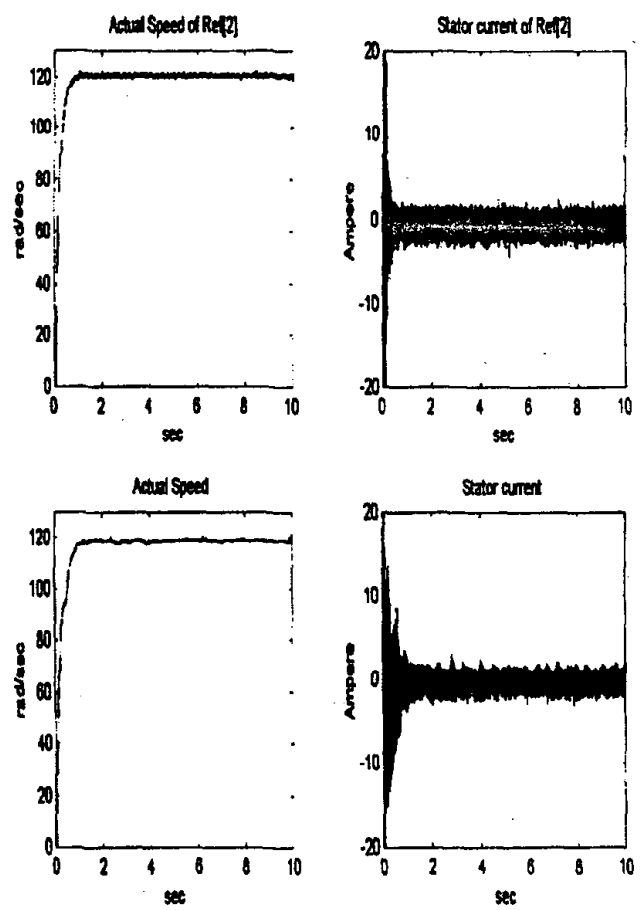

Fig.4 Experimental comparison of proposed scheme 